\title{
Comparative quantitative proteomics of prochlorococcus ecotypes to a decrease in environmental phosphate concentrations
}

\author{
Matthew A Fuszard, Phillip C Wright and Catherine A Biggs
}

\begin{abstract}
Background: The well-lit surface waters of oligotrophic gyres significantly contribute to global primary production. Marine cyanobacteria of the genus Prochlorococcus are a major fraction of photosynthetic organisms within these areas. Labile phosphate is considered a limiting nutrient in some oligotrophic regions such as the Caribbean Sea, and as such it is crucial to understand the physiological response of primary producers such as Prochlorococcus to fluctuations in the availability of this critical nutrient.

Results: Prochlorococcus strains representing both high light (HL) (MIT9312) and low light (LL) (NATL2A and SS120) ecotypes were grown identically in phosphate depleted media $\left(10 \mu \mathrm{M} \mathrm{P}_{\mathrm{i}}\right)$. The three strains displayed marked differences in cellular protein expression, as determined by high throughput large scale quantitative proteomic analysis. The only strain to demonstrate a significantly different growth rate under reduced phosphate conditions was MIT9312. Additionally, there was a significant increase in phosphate-related proteins such as PhoE (> 15 fold increase) and a depression of the Rubisco protein $\mathrm{RbcL}$ abundance in this strain, whereas there appeared to be no significant change within the LL strain SS120.

Conclusions: This differential response between ecotypes highlights the relative importance of phosphate availability to each strain and from these results we draw the conclusion that the expression of phosphate acquisition mechanisms are activated at strain specific phosphate concentrations.
\end{abstract}

Keywords: Prochlorococcus, PstS, PhoA, PhoE, Growth, Phosphate

\section{Background}

Within marine oligotrophic systems, such as central subtropical gyres, orthophosphate $\left(\mathrm{P}_{\mathrm{i}}\right)$ is a crucial macronutrient governing microbial population densities, particularly within the well-lit surface waters of the euphotic zone [1-3]. The principal photosynthetic organism numerically dominating these areas is Prochlorococcus, which is estimated to represent about $50 \%$ of all photosynthetic activity within them $[4,5]$. Prochlorococcus has been broadly delineated into two clades, or ecotypes, high light (HL) and low light (LL) based upon the ratios of divinylchlorophyll $a$ and $b$ within their light harvesting apparatuses and as such their assumed depth within the water column $[6,7]$. Further clade

\footnotetext{
*Correspondence: c.biggs@sheffield.ac.uk

ChELSI Institute, Department of Chemical and Biological Engineering, University of Sheffield, Mappin Street, Sheffield S1 3JD, UK
}

subdivisions have been implemented through phylogenetic analyses of $16 \mathrm{~S}$ rRNA sequences [8]. As a taxon, Prochlorococcus is characterised by its small size $(\sim 1$ $\left.\mu \mathrm{m}^{3}\right)$, and significantly reduced genomes which ranges from 1.64 Mbps (the HL strain MIT9301) to 2.68 Mbps (the LL strain MIT9303) [9]. This diminished volume and genome is hypothesised to be the result of an accelerated evolutionary process adapting to reduced phosphorus in its environment $[10,11]$. Indeed, Prochlorococcus is known to replace phospholipids in its membranes with sulpholipids, which dramatically reduce its $\mathrm{P}_{\mathrm{i}}$ requirements [12].

Given the importance of $\mathrm{P}_{\mathrm{i}}$ to Prochlorococcus, perhaps it is surprising to find no significant correlation between ecotype distribution and $P_{i}$ concentration [13]. However, fluxes in $P_{i}$ transport within these regions are important considerations, which could help to explain
C Biomed Central

๑ 2012 Fuszard et al; licensee BioMed Central Ltd. This is an Open Access article distributed under the terms of the Creative Commons Attribution License (http://creativecommons.org/licenses/by/2.0), which permits unrestricted use, distribution, and reproduction in any medium, provided the original work is properly cited. 
the discrepancy. Nevertheless the observation of a large number of known $P_{i}$ acquisition genes in some LL ecotypes (i.e. MIT9313 and NATL2A), and not others (i.e. SS120) $[14,15]$ is confusing. Indeed, $P_{i}$ acquisition genes are present in some HL strains (i.e. MED4) and not others (i.e. MIT9515) [14]. However it was recently observed that the prevalence of Prochlorococcus genes involved in acquisition of phosphate substrates were correlated with areas of low $\mathrm{P}_{\mathrm{i}}$ such as the Caribbean Sea and NW Mediterranean [16]. This conflict is likely resolved due to the presence of hypervariable genomic islands within Prochlorococcus, allowing for evolutionarily rapid niche adaptation [17]. Given this, it was hypothesised that the presence or absence of these genes could directly affect the protein content of cells when $P_{i}$ stressed, and as such directly affect the ability of a strain to acclimate to environmental $P_{i}$ fluctuations [16]. So the question arises, how effective are cells with and without these genes at acclimating to a shift in environmental $\mathrm{P}_{\mathrm{i}}$ ? Indeed, the levels of mRNA transcripts of two strains, MED4 and MIT9313, which both contain the two component response regulation system phoBR, behaved quite differently to $P_{\mathrm{i}}$ starvation [14].

To address this we selected three strains, MIT9312, NATL2A and SS120, each representative of an ecotype and a position within the water column (Table 1). MIT9312 is a HLII strain isolated at depth from the Gulf Stream. NATL2A is a LLI strain isolated from the North Atlantic which contains most of the $P_{i}$ acquisition genes found in MED4 and MIT9312, and yet is thought to experience both high and low light environments due to storm mixing events. SS120, originally isolated in the
Sargasso Sea, does not possess phoBR, yet has two copies of the periplasmic phosphate binding protein, PstS. We took these three strains and allowed cells to acclimate to a significant reduction in environmental $P_{i}$ and investigated their respective protein contents.

\section{Results and discussion}

\section{Overview}

The experimental growth data for each strain under $P_{i}$ replete and $P_{i}$ deplete cultures is shown in Figure 1. Logistic curve fitting and statistical analysis of the experimental growth data reveals no significant differences between the growth rates between $P_{i}$ replete and $P_{i}$ deplete cultures, with the exception of MIT9312 growth rates whereby $P_{i}$ replete growth was significantly greater than $\mathrm{P}_{\mathrm{i}}$ deplete growth $(\mathrm{p}<0.05)$, as can be seen in Figure 1. It is important to consider the physiological status of the cells at the harvest point when considering protein relative abundances. Importantly, growth analysis shows that both MIT9312 and SS120 were in late exponential/early stationary phase at harvest, whilst NATL2A was in mid exponential phase. As the point of harvest differs for NATL2A, it would be difficult to directly compare the protein complement of NATL2A cells to either MIT9312 or SS120. Given this, the results for NATL2A will be discussed separately.

Thirty eight, 63 and 34 proteins were identified with 2 or more peptides for strains MIT9312, NATL2A and SS120 respectively (Additional file 1 : Table S1) with no false positives. An overview of the respective proteomes, through plotting theoretical values of isoelectric points $(p I)$ against molecular weights $(\mathrm{MW})$ reveal significant

Table 1 Details of the strains used in this study, as obtained from NCBI and CCMP.

\begin{tabular}{|c|c|c|c|c|c|c|c|c|}
\hline \multicolumn{9}{|c|}{ Strain and genome details } \\
\hline & & & \multirow{2}{*}{$\frac{\text { Genome }}{\text { size (Mbp) }}$} & \multirow{2}{*}{$\frac{\text { Protein }}{\text { coding }}$} & \multirow[t]{2}{*}{$\% G C$} & \multirow{2}{*}{$\begin{array}{l}\text { Chl b/a } \\
\text { ratio }\end{array}$} & \multicolumn{2}{|l|}{ Ecotypic } \\
\hline Strain & Refseq & Reference & & & & & clade & \\
\hline MIT9312 & NC_007577 & {$[18]^{\mathrm{a}}$} & 1.71 & 1810 & 31 & 0.34 & HLII & \\
\hline NATL2A & NC_007335 & [19] & 1.84 & 2162 & 35 & 0.97 & LLI & \\
\hline SS120 & NC_005042 & [20] & 1.75 & 1883 & 36 & 1.41 & LLII & \\
\hline \multicolumn{9}{|c|}{ P acquisition mechanisms } \\
\hline & PhoBR cluster & PtrA cluster & PhoA & PhoE & $\begin{array}{l}\text { PstS } \\
\text { cluster }\end{array}$ & $\begin{array}{l}\text { ArsA } \\
\text { cluster }\end{array}$ & ArsB cluster & ArsC cluster \\
\hline MIT9312 & $\sqrt{ }$ & $x$ & $\sqrt{ }$ & $\sqrt{ }$ & $\sqrt{ }$ & $\sqrt{ }$ & $x$ & $\sqrt{ }$ \\
\hline NATL2A & $\sqrt{ }$ & $\sqrt{ }$ & $\sqrt{ }$ & $\sqrt{ }$ & $\sqrt{ }$ & $\sqrt{ }$ & $x$ & $\sqrt{ }$ \\
\hline SS120 & $x$ & $\sqrt{ }$ & $x$ & $x$ & (2) & $x$ & $x$ & $\sqrt{ }$ \\
\hline \multicolumn{9}{|c|}{ Isolation details and culture conditions } \\
\hline & Location & Depth & Isolated by & Date & Culture temp $\left({ }^{\circ} \mathrm{C}\right)$ & $\begin{array}{l}\text { Deposited } \\
\text { in }\end{array}$ & Media & \\
\hline MIT9312 & Gulf stream & $135 \mathrm{~m}$ & L. Moore & 17/07/1993 & $22-26$ & CCMP & Pro99 & \\
\hline NATL2A & N. Atlantic & $10 \mathrm{~m}$ & D. Scanlan & 01/04/1990 & $18-22$ & CCMP & Pro99 & \\
\hline SS120 & Sargasso Sea & $120 \mathrm{~m}$ & S. Frankel \& L West-Johnsrud & $01 / 01 / 1991$ & $18-22$ & CCMP & Pro99 & \\
\hline
\end{tabular}

${ }^{\mathrm{a}}$ indicates that the genome sequence has been submitted, yet not cleared. Ticks in ' $P$ acquisition mechanisms' indicates presence of gene/cluster, and copies are in parentheses 


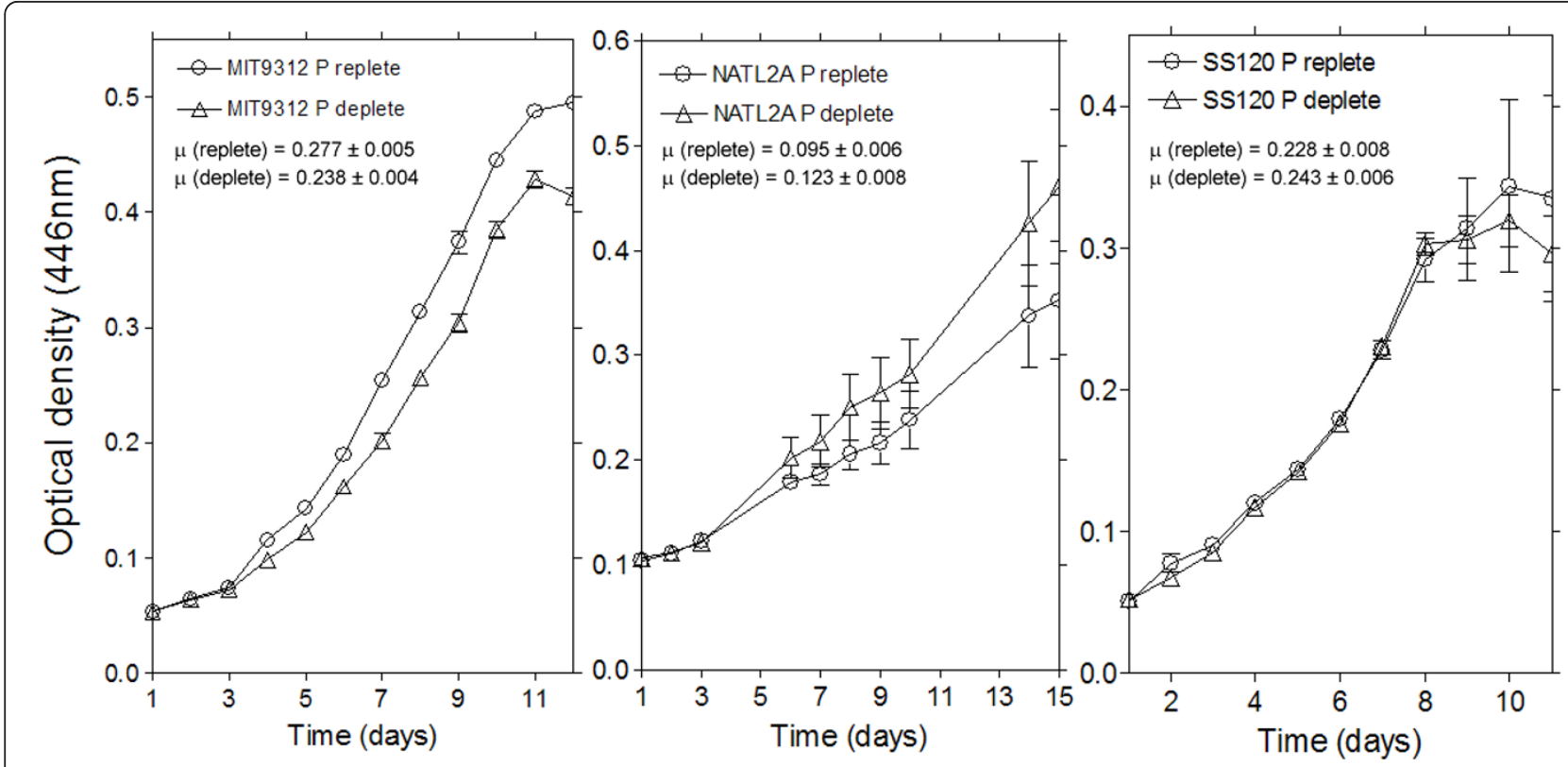

Figure 1 Experimental growth curves of MIT9312, NATL2A and SS120 within $\mathrm{P}_{\mathrm{i}}$ replete (circles) and $\mathrm{P}_{\mathrm{i}}$ deplete (triangles) media. Error bars represent one standard error. Growth rates $(\mu)$ are given with \pm standard error.

bias towards low $p I$ values (Additional file 2: Figure S1), with no further correlation to MW, relative protein abundance, nor total peptide hits per protein (data not shown). This bias may be an artefact of the mass spectrometric analysis, where peptides are protonated directly before entry into the MS in order to assist flight and detection. As a consequence, naturally occurring proton-donor peptides may be preferentially selected. However, as there are no observable correlations between $P I$ and peptide hits per protein, we can be confident that the intracellular protein abundances reported are directly reflective of the physiological status of the cells. Indeed, when interrogating the proportion of proteins with $\geq 50 \%$ of peptide hits, we see similarities between strains, such as the presence of RplL, RbcL and CsoS1 (Additional file 1: Table S1), however all three proteins have $p I$ values $<7$. Nevertheless, a high $p I$ protein, PetH, is present in both MIT 9312 and SS120 samples. Also, identified proteins from all three strains are located evenly across the genomes, and are representative of most major functional groups such as central metabolism, photosynthesis, transcription and translation, biosynthesis and nutrient acquisition (Figure 2A). Of the 105 unique proteins identified, 6 were found in all three strains (Figure 2B). They are the ATP synthase subunits AtpA and AtpD, the PSII protein PsbO, the nitrogen regulatory protein GlnK, rubisco subunit RbcL, and the carboxysome shell protein CsoS1.

Using relative abundance cut-offs of 1.6 and 0.6 fold differences to represent increased or decreased relative abundances [21,22], 4 proteins were more abundant in MIT9312 and 4 were less abundant than the replete cultures. Within NATL2A, 6 proteins were more abundant and 1 was less abundant than the replete cultures. In SS120, 4 were more abundant and none were lower than the replete cultures (Figure 2A).

\section{Nutrient acquisition}

What is immediately apparent from our results is the differential abundance of $\mathrm{P}_{\mathrm{i}}$ acquisition proteins exhibited by all three strains to being grown in $10 \mu \mathrm{M} \mathrm{P} \mathrm{P}_{\mathrm{i}}$. MIT 9312 demonstrates the greatest sensitivity to $P_{i-}$ deplete media, whereby the $\mathrm{P}_{\mathrm{i}}$ stress related porinPhoE is $>15$-fold more abundant (Figure 3 ), the putative alkaline phosphatase PhoA appears to be $>$ 9-fold greater, and the periplasmic $\mathrm{P}_{\mathrm{i}}$ binding protein PstS $>3$ times more than the replete cultures. This result is directly in line with an earlier proteomic assay of $\mathrm{P}$ stress in a HL ecotype, MED4 [21], and closely reflective of microarray analyses of both MED4 and MIT9313 [14], Synechococcucs WH8102 [23], measured alkaline phosphatase activity of MIT9312 [15] and in line with observed responses within earlier $P_{i}$ depletion studies of other cyanobacteria [15,24-26].

Within NATL2A, PstS abundance is significantly greater within $\mathrm{P}_{\mathrm{i}}$-deplete conditions, though with greater uncertainty (Additional file 1: Table S1). However neither PhoA nor PhoE was observed with mass spectrometry here, which is surprising as we showed previously that both PhoA and PhoE are greater in 


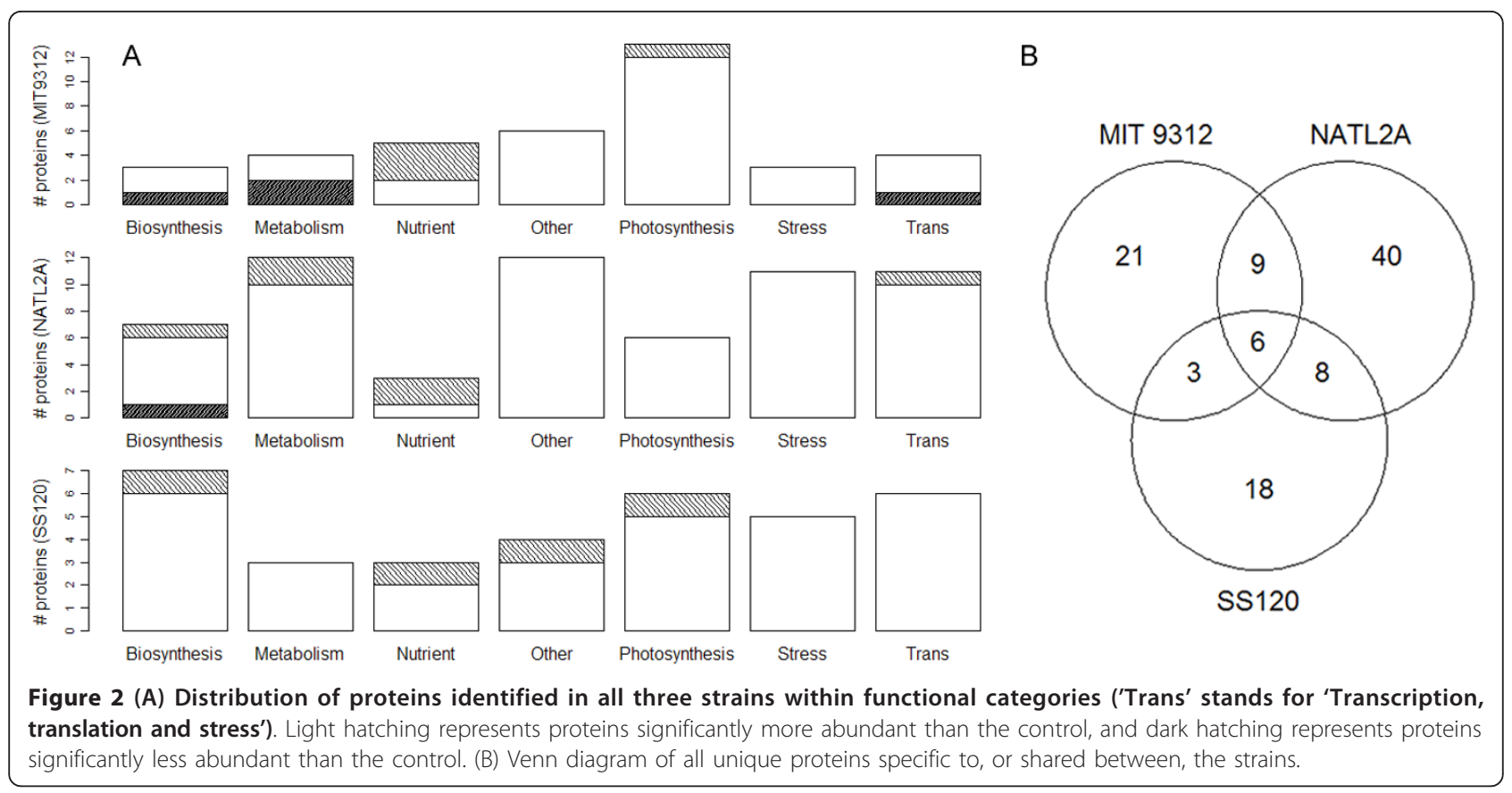

abundance alongside PstS in the high light ecotype MED4 [21], as is true with MIT9312 in this study. However, considering that NATL2A cells are in midexponential phase as opposed to early stationary phase this may indicate a progressive strategy of protein expression within the cells, however more work is needed to clarify this.

What was also unexpected, was the absence of any $\mathrm{P}_{\mathrm{i}}$ acquisition mechanisms (as reflected in observed peptide identifications) within SS120 cells (Additional file 1: Table S1), allied with no significant difference in growth rates between $\mathrm{P}_{\mathrm{i}}$-replete and $\mathrm{P}_{\mathrm{i}}$-deplete cultures $(\mathrm{p}>$ $0.05)$. SS120 is deficient in most $P_{i}$ acquisition genes $[14,15]$, however it does have two copies of PstS, neither of which were present in our assay. At first glance, this

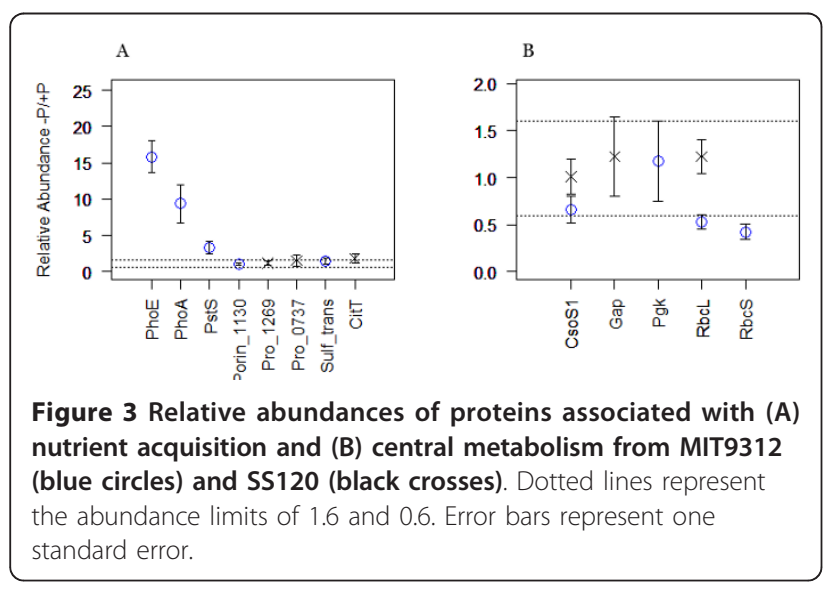

result appears counter-intuitive, as a 'very' LL strain typically present in vivo within $\mathrm{P}_{\mathrm{i}}$-replete environments would be expected to be adversely affected by a substantial decrease in $\mathrm{P}_{\mathrm{i}}$. However, the absence of a phoBRregulon suggests that the strain is incapable of regulating a response to shifts in environmental concentrations of $\mathrm{P}_{\mathrm{i}}$ that are not immediately starvation inducing [27]. Curiously, this also infers that activation of the phoBR response mechanisms within MIT9312 and NATL2A were directly due to the mechanism's innate sensitivity to changing external $\mathrm{P}_{\mathrm{i}}$ concentrations. This suggests that the intensity of response is directly proportional to external $\mathrm{P}_{\mathrm{i}}$ concentration, coincidentally specific to each strain, and may be reflective of each strain's environmental niche and/or obligate cellular requirements.

\section{Photosynthesis, biosynthesis and central metabolism}

The exposure of all three strains to lower $P_{i}$ concentrations appears to have had little effect upon the photosynthetic machinery (Figure 4A and Additional file 1: Table S1). This is unusual, as $\mathrm{P}_{\mathrm{i}}$ depleted conditions have been previously noted to directly affect both photosystems in cyanobacteria $[21,23,28]$. In contrast, it is interesting to note that, for MIT9312, both Rubisco subunits (RbcL and RbcS) are noticeably lower in abundance (Figure $3 \mathrm{~B}$ ). This suggests that there is a progressive strategy within the cell when acclimating to lowered $\mathrm{P}_{\mathrm{i}}$, whereby photosynthesis is initially dissociated from glycolysis, to then strategically break down the photosynthetic apparatus. This is a reasonable conclusion, considering a $\mathrm{P}_{\mathrm{i}}$-induced organised break down 


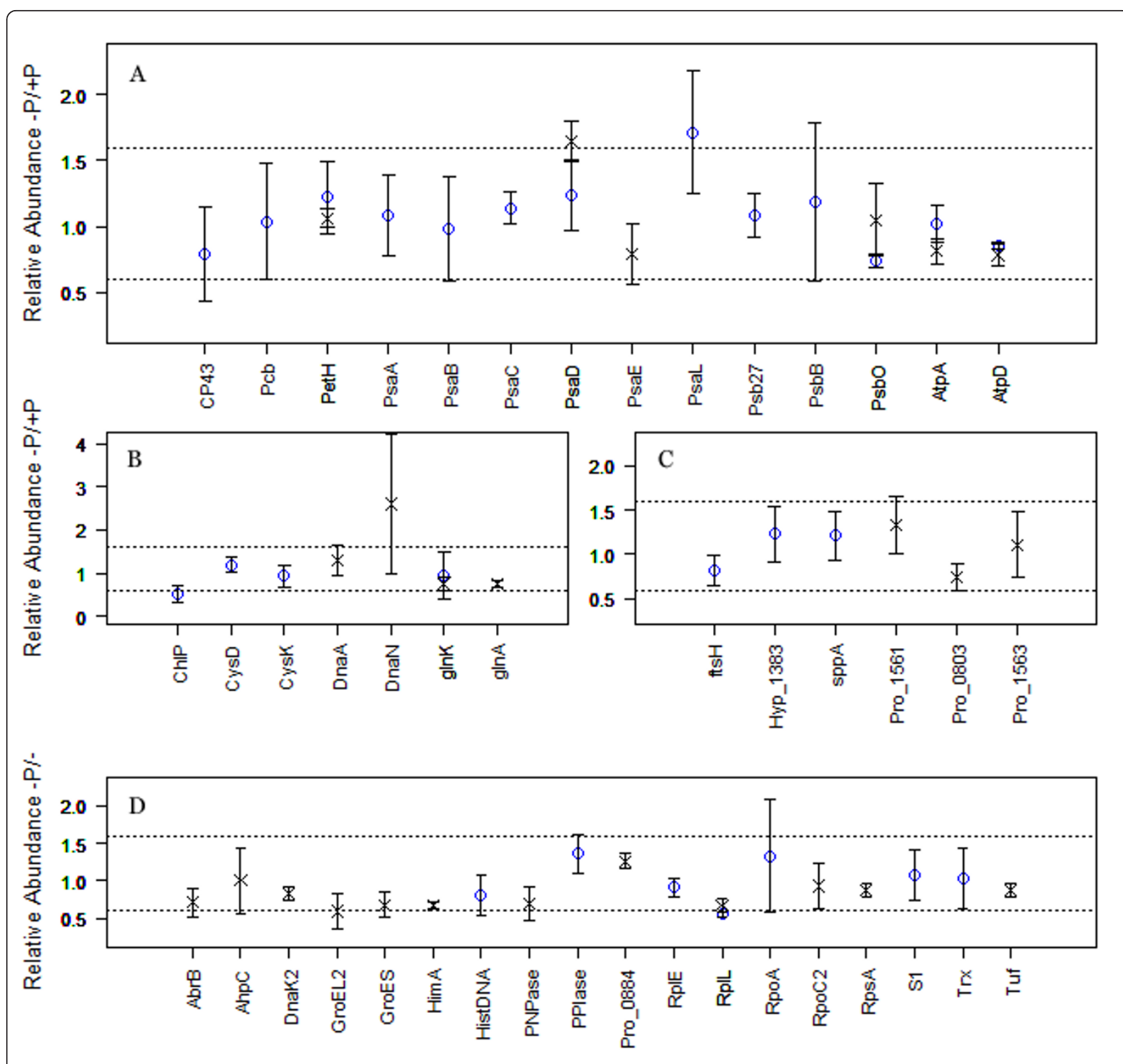

Figure 4 Relative abundances of proteins associated with (A) photosynthesis, (B) biosynthesis, (C) uncategorised and (D) transcription, translation and stress from MIT9312 (blue circles) and SS120 (crosses). Dotted lines represent the abundance limits of 1.6 and 0.6. Error bars represent one standard error.

of phycobilisomes has been previously observed in Synechococcus sp. PCC 7942 [29], chlorosis has been observed in thermophillicSynechococcus under $\mathrm{P}_{\mathrm{i}}$-stress [28], and a strategic approach to a reduction in photosynthetic function has been hypothesised in MED4 [21]. Indeed, within WH8102 it appears that PSII was degraded before PSI, allowing continued cyclic photophosphorylation-based ATP generation to continue [23]. In this context, this could explain why an essential chlorophyll biosynthetic protein (ChlP) appears to be less abundant within $\mathrm{P}_{\mathrm{i}}$-deplete MIT9312 cells (Figure
4B). However, it would be parsimonious to also expect a concurrent reduction in the light harvesting protein (Pcb) within $\mathrm{P}_{\mathrm{i}}$-deplete MIT9312, which was noticed in MED4 [21], but there is no change. The reason for this is not clear.

When considering NATL2A solely, there appear to be a few subtle discrepancies in protein abundances between stressed and non-stressed cultures. Fumerase (FumC) is an enzyme associated with both the tricarboxylic acid (TCA) cycle and arginine/proline biosynthesis, and appears to be more abundant within NATL2A 
cells when $\mathrm{P}_{\mathrm{i}}$-deplete (Additional file 1: Table S1). As NATL2A has an incomplete TCA cycle, it is safe to assume that its function within the cell is within arginine and proline metabolism. Also, the acyl carrier protein (AcpP) is an essential component of fatty acid biosynthesis, and is more abundant in $\mathrm{P}_{\mathrm{i}}$-deplete NATL2A cells (Additional file 1: Table S1). Fatty acids are for the most part used within either fuel storage or membrane manufacture. However it may be misleading to arrive at the conclusion that this is a specific cellular response to lower $P_{i}$ concentrations. It is possibly a function of apparently slightly elevated (albeit not significant) growth within NATL2A $\mathrm{P}_{\mathrm{i}}$-deplete cultures, and as such could reflect comparatively greater metabolic activity. Nevertheless, this explanation cannot immediately address the lower abundance of CobJ, a Precorrin3B C17-methyltransferase region-containing protein (Additional file 1: Table S1), part of the aerobic vitamin B12 biosynthesis pathway within $\mathrm{P}_{\mathrm{i}}$-stressed cells. However, B12 synthesis is a sub pathway offshoot from the main chlorophyll biosynthetic pathway, and as such may reflect a metabolic preference for chlorophyll production that, again, may be representative of faster growing populations.

An interesting observation is the abundance of CitT within $\mathrm{P}_{\mathrm{i}}$-stressed SS120 cells (Figure 3A). This protein functions as a di/tricarboxylate transporter, which implies that the cells are scavenging lysed cellular material from the environment. That stressed SS120 cells appear to be preferentially acquiring tricarboxylic acid intermediates when growing in $\mathrm{P}_{\mathrm{i}}$-deplete conditions, and not upregulatingPstS, is puzzling. However, it may indicate that this strain may be supplementing an affected glycolysis pathway through acquiring external carbon sources, and that this is more evidence that the cells response to an environmental stress is an iterative, evolving process. SS120 may simply have not initiated transcription of PstS in sufficiently detectable quantities. Indeed, even in starvation experiments pstSexperession is far from an immediate response [14,23].

\section{Other proteins}

An interesting observation is the presence of LuxR, the response regulatory family protein involved in quorum sensing within bacteria, in NATL2A cells (Additional file 1: Table S1). To our knowledge, this is the first instance of observing proteins putatively indicated in quorum sensing capability in any marine cyanobacteria. However, we were unable to locate any LuxI homologues, an essential protein required for effective quorum sensing, within NATL2A (data not shown). However LuxR is known to be a transcriptional regulator activated when cell concentrations of a particular trigger compound (usually $\mathrm{N}$-(3-oxohexanoyl) ${ }_{\mathrm{L}}$-homoserine lactone, which is generated through the enzymatic functioning of LuxI) reach particular levels. As such, we speculate that the protein acts as a density-dependant transcriptional regulator, but for an unknown function, and through another trigger compound.

\section{Conclusions}

Prochlorococcus are now widely considered to be evolutionarily adept at environmental niche domination, particularly within nutrient poor oligotrophic waters. The genus is typified by genomes characterised by hypervariable genomic islands [17], which are thought to contain genes obtained through phage-mediated horizontal gene transfer, and infer niche-specific advantages such as nutrient acquisition and phage resistance. Our results reinforce previous results concerning the importance of phosphate concentrations to specific strains, but also highlight the possibility of the cells employing a progressive acclimation strategy. It appears that Prochlorococcus strains evolutionarily adapted to life in a $\mathrm{P}_{\mathrm{i}}$-deplete environment respond to phosphate fluctuations through a succession of cellular processes, such as the upregulation of $\mathrm{P}_{\mathrm{i}}$ acquisition mechanisms, a dissociation of photosynthesis from central metabolic pathways, and a staggered breakdown of the photosystems allowing prolonged photophosphorylated ATP generation. This progressive response allows the cell to react quickly to any subsequent increases in ambient $\mathrm{P}_{\mathrm{i}}$ concentrations. It is our hypothesis that HL strains are also particularly sensitive to changes in $\mathrm{P}_{\mathrm{i}}$, and that ambient phosphate concentrations initiate a strong response regardless of being predominantly growth limited elsewhere.

We also note that our results strongly infer that the induction of $\mathrm{P}_{\mathrm{i}}$ acquisition mechanisms are concentration specific between strains, particularly considering the absence of any stress response of the LL strain SS120 compared to MIT9312 when grown from identical initial concentration levels.

\section{Methods}

For a complete description of the Materials and Methods used please refer to the (Additional file 3: Material and Methods). In brief, however, biological triplicates of all three strains (MIT9312, NATL2A and SS120 (CCMP, Maine)) were grown under 2 separate conditions: $P_{i}$ replete (Pro99 media with $50 \mu \mathrm{M} \mathrm{NaH}{ }_{2} \mathrm{PO}_{4}$ [30]) and $\mathrm{P}_{\mathrm{i}}$ deplete (Pro99 media with $10 \mu \mathrm{M}$ $\mathrm{NaH}_{2} \mathrm{PO}_{4}$ ), and moderate white light intensities (30, 10 and $20 \mu \mathrm{E} \mathrm{m}^{-2} \mathrm{~s}^{-1}$ respectively), in a 13:11 h light:dark regime at $23^{\circ} \mathrm{C}$.

For the proteomic analysis, the cells were harvested once measured optical densities reached 0.4 (after which populations had been observed to crash), and proteins were extracted from the three biological replicates for 
each phenotype [31]. $100 \mu \mathrm{g}$ of protein from each replicate was then reduced, alkylated, digested and labelled with 8-plex iTRAQ reagents according to the manufacturer's (ABSciex, Framingham, MA) protocol. The labelled replicates were then pooled before primary strong cation exchange (SCX) fractionation [21]. Mass spectrometric analysis of the SCX fractions was performed with a QStar XL Hybrid ESI Quadrupole timeof-flight tandem mass spectrometer, ESI-qQ-TOF-MS/ MS (Applied Biosystems; MDS Sciex, Concord, Ontario, Canada), coupled with an online capillary liquid chromatography system (Ultimate 3000, Dionex/LC Packings, The Netherlands) [21,22]. Preliminary data analysis, protein identification and quantitation were carried out using the PHENYX [Geneva Bioinformatics (GeneBio), Geneva, Switzerland] software platform.

\section{Additional material}

Additional file 1: Table S1. Full list of identified proteins and peptides for all 3 strains used in this study.

Additional file 2: Figure S1. Virtual 2D gel representations of proteins identified from MIT9312 (top left), NATL2A (top right), and SS120 (bottom left).

Additional file 3: Materials and methods [32-34].

\section{Acknowledgements}

The authors wish to acknowledge the provision of an EPSRC studentship, Advanced Research Fellowship for CAB (EP/E053556/01) and further EPSRC funding (GR/S84347/01 and EP/E036252/1). We also acknowledge the Provasoli-Guillard National Center for Culture of Marine Phytoplankton for the kind provision of cells. Thanks also to Adam Martiny for additional input.

\section{Authors' contributions}

MAF designed the study, carried out the proteomics, analysed the data and drafted the manuscript. PCW and CAB conceived of the study and participated in its design. All authors read and approved the final manuscript.

\section{Competing interests}

The authors declare that they have no competing interests.

Received: 8 November 2011 Accepted: 19 March 2012 Published: 19 March 2012

\section{References}

1. Ammerman JW, Hood RR, Case DA, Cotner JB: Phosphorus deficiency in the Atlantic: An emerging paradigm in oceanography. Eos Trans Am Geophys Union 2003, 84:165-170.

2. Thingstad TF, Krom MD, Mantoura RF, et al: Nature of phosphorus limitation in the ultraoligotrophic eastern Mediterranean. Science 2005, 309:1068-1071.

3. Thingstad TF, Zweifel UL, Rassoulzadegan F: P limitation of heterotrophic bacteria and phytoplankton in the northwest Mediterranean. Limnol Oceanogr 1998, 43:88-94

4. Chisholm SW, Olson RJ, Zettler ER, Goericke R, Waterbury JB, Welschmeyer NA: A novel free-living prochlorophyte abundant in the oceanic euphotic zone. Nature 1988, 334:340-343.

5. Partensky F, Hess WR, Vaulot D: Prochlorococcus, a marine photosynthetic prokaryote of global significance. Microbiol Mol Biol Rev 1999, 63:106-127.
6. Moore LR, Chisholm SW: Photophysiology of the marine cyanobacterium Prochlorococcus: ecotypic differences among cultured isolates. Limnol Oceanogr 1999, 44:628-638.

7. Moore LR, Rocap G, Chisholm SW: Physiology and molecular phylogeny of coexisting Prochlorococcus ecotypes. Nature 1998, 393:464-467.

8. Rocap G, Distel DL, Waterbury JB, Chisholm SW: Resolution of Prochlorococcus and Synechococcus ecotypes by using 16S-23S ribosomal DNA internal transcribed spacer sequences. Appl Environ Microbiol 2002, 68:1180-1191.

9. Partensky F, Garczarek L: Prochlorococcus: Advantages and Limits of Minimalism. Ann Rev Marine Sci 2009, 2:305-331.

10. Coleman ML, Chisholm SW: Ecosystem-specific selection pressures revealed through comparative population genomics. ProcNat/AcadSci 2010, 107:18634-18639.

11. Dufresne A, Garczarek L, Partensky F: Accelerated evolution associated with genome reduction in a free-living prokaryote. Genome Biol 2005, 6 R14.

12. Van Mooy BA, Rocap G, Fredricks HF, Evans CT, Devol AH: Sulfolipids dramatically decrease phosphorus demand by picocyanobacteria in oligotrophic marine environments. Proc Natl Acad Sci USA 2006, 103:8607-8612

13. Johnson ZI, Zinser ER, Coe A, McNulty NP, Woodward EM, Chisholm SW: Niche partitioning among Prochlorococcus ecotypes along ocean-scale environmental gradients. Science 2006, 311:1737-1740.

14. Martiny AC, Coleman ML, Chisholm SW: Phosphate acquisition genes in Prochlorococcus ecotypes: evidence for genome-wide adaptation. Proc Natl Acad Sci USA 2006, 103:12552-12557.

15. Moore LR, Ostrowski M, Scanlan DJ, Feren K, Sweetsir T: Ecotypic variation in phosphorus-acquisition mechanisms within marine picocyanobacteria. AquatMicrobEcol 2005, 39:257-269.

16. Martiny AC, Huang Y, Li W: Occurrence of phosphate acquisition genes in Prochlorococcus cells from different ocean regions. Environ Microbiol 2009, 11:1340-1347.

17. Coleman ML, Sullivan MB, Martiny AC, Steglich C, Barry K, Delong EF, Chisholm SW: Genomic islands and the ecology and evolution of Prochlorococcus. Science 2006, 311:1768-1770.

18. Copeland A, Lucas S, Lapidus A, Barry K, Detter JC, Hammon N, Israni S, Pitluck S, Thiel J, Schmutz J, Larimer F, Land M, Kyrpides N, Lykidis A, Richardson P: Complete sequence of Prochlorococcus marinus str. MIT 2005, 9312, Unpublished.

19. Kettler GC, Martiny AC, Huang K, Zucker J, Coleman ML, Rodrigue S, Chen F, Lapidus A, Ferriera S, Johnson J, et al: Patterns and implications of gene gain and loss in the evolution of Prochlorococcus. PLoS Genet 2007, 3: e231.

20. Dufresne A, Salanoubat M, Partensky F, Artiguenave F, Axmann IM, Barbe $V$, Duprat S, Galperin MY, Koonin EV, Le Gall F, Makarova KS, Ostrowski M, Oztas S, Robert C, Rogozin IB, Scanlan DJ, Tandeau de Marsac N, Weissenbach J, Wincker P, Wolf YI, Hess WR: Genome sequence of the cyanobacterium Prochlorococcus marinus SS120, a nearly minimal oxyphototrophic genome. Proc Natl Acad Sci USA 2003, 100(17):10020-10025

21. Fuszard MA, Wright PC, Biggs CA: Cellular acclimation strategies of a minimal picocyanobacterium to phosphate stress. FEMS MicrobiolLett 2010, 306:127-134

22. Pandhal J, Wright PC, Biggs CA: A quantitative proteomic analysis of light adaptation in a globally significant marine cyanobacterium Prochlorococcus marinus MED4. J Proteome Res 2007, 6:996-1005.

23. Tetu SG, Brahamsha B, Johnson DA, Tai V, Phillippy K, Palenik B, Paulsen IT: Microarray analysis of phosphate regulation in the marine cyanobacterium Synechococcus sp. WH8102. ISME J 2009, 3:835-849.

24. Huber AL, Hamel KS: Phosphatase activities in relation to phosphorus nutrition in Nodularia spumigen (Cyanobacteriaceae). Hydrobiologia 1985, 123:81-88.

25. Natesan R, Shanmugasundaram S: Extracellular phosphate solubilization by the cyanobacterium Anabaena ARM310. J Biosci 1989, 14:203-208.

26. Scanlan DJ, Mann NH, Carr NG: The response of the picoplanktonic marine cyanobacterium Synechococcus species WH7803 to phosphate starvation involves a protein homologous to the periplasmic phosphate-binding protein of Escherichia coli. Mol Microbiol 1993, 10:181-191. 
27. Scanlan DJ, West NJ: Molecular ecology of the marine cyanobacterial genera Prochlorococcus and Synechococcus. FEMS Microbiol Ecol 2002, 40:1-12.

28. Adams MM, Gomez-Garcia MR, Grossman AR, Bhaya D: Phosphorus Deprivation Responses and Phosphonate Utilization in a Thermophilic Synechococcus sp. from Microbial Mats. J Bacteriol 2008, 190:8171-8184.

29. Collier JL, Grossman AR: Chlorosis induced by nutrient deprivation in Synechococcus sp. strain PCC 7942: not all bleaching is the same. J Bacteriol 1992, 174:4718-4726.

30. Moore LR, Post AF, Rocap G, Chisholm SW: Utilization of Different Nitrogen Sources by the Marine Cyanobacteria Prochlorococcus and Synechococcus. LimnolOceanogr 2002, 47:989-996.

31. Meijer EA, Wijffels RH: Development of a Fast, Reproducible and Effective Method for the Extraction and Quantification of Proteins of Micro-algae. Biotechnol Tech 1998, 12:353-358.

32. Moore LR, Goericke R, Chisholm SW: Comparative physiology of Synechococcus and Prochlorococcus: Influence of light and temperature on growth, pigments, fluorescence and absorptive properties. Mar Ecol Prog Ser 1995, 116:259-276.

33. Ow SY, Noirel J, Cardona T, Taton A, Lindblad P, Stensjo K, Wright PC: Quantitative Overview of N2 Fixation in Nostoc punctiforme ATCC 29133 through Cellular Enrichments and iTRAQ Shotgun Proteomics. Journal Proteome Research 2009, 8:187-198.

34. Team RDC: R: A Language and Environment for Statistical Computing R Foundation for Statistical Computing: Vienna, Austria; 2011.

doi:10.1186/2046-9063-8-7

Cite this article as: Fuszard et al:: Comparative quantitative proteomics of prochlorococcus ecotypes to a decrease in environmental phosphate concentrations. Aquatic Biosystems 2012 8:7.

\section{Submit your next manuscript to BioMed Central and take full advantage of:}

- Convenient online submission

- Thorough peer review

- No space constraints or color figure charges

- Immediate publication on acceptance

- Inclusion in PubMed, CAS, Scopus and Google Scholar

- Research which is freely available for redistribution

Submit your manuscript at www.biomedcentral.com/submit 